http://doi.org/10.15359/ree.13-2.10

\title{
Fundamentos teóricos de la Educación Universitaria, sus artífices e incidencias en el currículo promovido
}

\author{
Carolina España Chavarría ${ }^{1}$ \\ Académica de la Escuela de Secretariado Profesional de la Universidad Nacional \\ Heredia, Costa Rica
}

Recibido 21 de agosto de $2008 \bullet$ Aceptado 29 de abril de 2009

\begin{abstract}
Resumen. Es posible pensar que al igual que la política nutre el currículo, la pedagogía, en su arte práctica, supone ser su abono para el cultivo de aprendizajes en la vida. Esto significa que el docente con formación pedagógica puede estar en capacidad de transformar su conocimiento disciplinar en un aprendizaje de conocimiento entendible, práctico y con sentido, por cuanto recurre a la pedagogía como el instrumento que le facilita viabilizar la política curricular en aras de convertir el proceso educativo en uno de calidad.

Asimismo, se considera que gran parte de la profesionalización docente podría radicar en la continuidad de la formación del profesorado o formación permanente, cuyo resultado es el desarrollo profesional del profesorado y, consecuentemente, del alumnado, para que, de este proceso, se geste, "conocimiento al servicio de la vida, del elevamiento de la calidad de vida" (Flores, 1994, p. XXV), es decir, aprendizajes significativos producto de modelos de enseñanza acordes con lo que dicta y busca la propuesta curricular promovida.
\end{abstract}

Palabras clave. Política curricular, currículo (explícito y oculto), profesorado, formación pedagógica, desarrollo profesional, autonomía docente, formación permanente, modelos de enseñanza.

Abstract. It is possible to think, that as well as the policies enrich the curriculum the pedagogy in its practical art pretends to be the necessary input to foster knowledge in life. This means, that the educator with pedagogical training could be capable of transforming disciplinary knowledge into an understandable, practical, and meaningful one, due to the fact that they turn pedagogy as the instrument that will allow them to put the curricular policy into practice, transforming the educational process into a process of quality.

\footnotetext{
${ }^{1}$ Estudiante del Doctorado en Políticas y Prácticas de Innovación Educativa para la Sociedad del Conocimiento por la Universidad de Almería, España. Magíster en Políticas y Prácticas de Innovación Educativa para la Sociedad del Conocimiento por la Universidad de Almería, España. Magíster en Segundas Lenguas y Culturas con Énfasis en Inglés como Lengua extranjera para: Alumnado Adulto, por la Universidad Nacional, Costa Rica. Docente en el área de la educación y enseñanza del inglés. Actualmente, labora en la Escuela de Secretariado Profesional de la Universidad Nacional. Cuenta con ponencias y asesorías internacionales realizadas en la USAC (Universidad de San Carlos, Guatemala): Técnicas para la comunicación oral en inglés orientada a la locución, Estrategias y metodologías de la enseñanza del idioma inglés, Técnicas para la comunicación oral en inglés orientada al periodismo, Profesionalización del colectivo docente de la escuela de lingüística.

Correo electrónico: cespanac@yahoo.com.mx
} 
Moreover, we consider that most part of the professionalization of teaching could depend on a continuous or permanent process of faculty training, resulting in the professional growth of teachers and consequently of students. This process will evoke "knowledge to the service of life and to the improvement of quality of life" (Flores, 1994, p. XXV), which means meaningful learning due to teaching methods in agreement with what the curricular proposal dictates and looks for.

Key words. Curricular policies, curriculum (explicit and hidden), teachers, teacher's training, pedagogical training, professional development, teacher's autonomy, permanent training, teaching methods.

\section{Introducción}

El conocer los postulados teóricos que dan vida al acontecer universitario es de vital importancia, se coincide en que para hacer es necesario saber hacer. Para tal efecto, se iniciará esta travesía de comprensión teórico-curricular evidenciando algunos de los artífices de la educación universitaria y sus incidencias en el currículo promovido, no obstante, son múltiples las interpretaciones al respecto en manos de expertos, y es posible coincidir con algunas de ellas.

Como referencia histórica y de acuerdo con Menin (2001), el término currículo deriva del latín curriculum, sin embargo, se cree que llegó a dominios latinoamericanos por la vía del imperio de la penetración pedagógica norteamericana, a mediados de los años 40 del siglo anterior, con su mayor exponente: John Dewey.

Por tanto, es posible creer que el currículo se aleja de poseer características rígidas y determinadas, por tanto, su carácter es más bien flexible y dinámico, lo que permite no sólo redescubrirlo para una posible renovación, sino que, también, podría considerársele como el motor mismo de la gestión de un conocimiento, con características igualmente flexibles y dinámicas, de allí que el "el currículo constituye una especificación que resulta hipotética, abierta a interrogantes y a comprobación y dentro de la cual se construye y se gestiona el conocimiento" (Stenhouse, 2004, p. 93). Al respecto, Blanco (1997) considera que el currículo logra desplazarse en el difuso y amplio terreno en el que convergen los planos político, administrativo y educativo, de ahí la dificultad que implica reconocer los límites de cada plano.

Esta consideración sobre el currículo permite valorar la amplitud descrita también por Blanco, como parte de la importancia que el currículo tiene en la promoción de aprendizajes, pues lo que se vivencia fuera y dentro del aula se admite como insumo para la gestión curricular y según expertos “...el currículo se ocuparía preferentemente en sistematizar los aprendizajes no estrictamente escolares, es decir, los aprendizajes ampliados pero a partir del aula" (Menin, 2001, p. 130).

Asimismo, "el currículo ha estado ligado a la determinación de lo que ha de enseñarse en las escuelas, con un énfasis en el orden y la secuencia con que debe ser enseñado y aprendido" (Blanco, 1997, p. 9). En relación con las palabras de Blanco, es posible pensar que es de la política curricular que se deriva el qué, el cuándo y el cómo se debe enseñar, en otras palabras, podría deducirse que en la política curricular subyace la práctica pedagógica, es decir, ambas no están desligadas de la materia curricular, por el contrario, una se deriva de la otra.

Lo anterior conduce al umbral de las políticas curriculares, las cuales, según Blanco (1997), tienen sus orígenes en los años 50 y fueron establecidas, casi de forma exclusiva, por expertos norteamericanos y británicos. Asimismo, Blanco afirma que, para entonces, las políticas curriculares eran utilizadas, exclusivamente, para referirse a los procesos de toma de decisiones, el papel de los especialistas o los modelos de legitimación del currículo. 
Como se ha expuesto anteriormente, expertos aluden a una vinculación real entre política curricular y proceso pedagógico, razón por la cual es necesario conocer el significado otorgado por dichas autoridades al profesorado y la formación pedagógica, ambos considerados ingredientes fundamentales en el logro de una educación de calidad que visualiza el currículo como el medio que conduce al desarrollo pedagógico.

\section{Profesorado y formación pedagógica}

El profesorado, según Díez y Román (2004), es el que tiene la responsabilidad de generar modelos de enseñanza basada en procesos, ya que, en primera instancia, el colectivo docente supone acudir a los procesos de aprendizaje necesarios que respondan al cómo aprender de su alumnado. Por tanto, los procesos desarrollados por el colectivo docente para la promoción de aprendizajes, condicionarán los índices de calidad educativa.

Igualmente, se coincide con la premisa de que la especificación del currículo brinda al docente el uso de la interacción crítica entre ideas y planes educativos y, por supuesto, estos planes con su práctica pedagógica (Stenhouse, 2004) De ahí suponemos, el practicum reflexivo en la formación docente para el logro de la crítica entre ideas y propuestas educativas que señala Stenhouse, las cuales se consideran características vitales del profesorado y, quizás, una de las principales actividades en la que se supone gira la docencia universitaria.

Por lo anterior, es posible pensar que al igual que la política nutre el currículo, la pedagogía, en su arte práctica, supone ser el abono para el cultivo de aprendizajes en la vida. De ahí la importancia de la formación pedagógica del colectivo docente como complemento de su formación disciplinar, ya que, en coincidencia con Menin (2001), quien define a la pedagogía como "la práctica de la enseñanza”, se supone que la formación pedagógica de los docentes podría facilitar el desarrollo de estrategias de aprendizaje que permitan compartir conocimiento disciplinar mediante un mejoramiento de las experiencias educativas del alumnado y, consecuentemente, mejorar el currículo.

Entonces, podemos entender que la importancia de la formación pedagógica del profesorado está ligada al logro de los fines de la educación en el marco de un currículo actual de características integrales, flexibles y dinámicas, con visión innovadora y de significancia potencial para todos los artífices de la educación. También podría definirse como "la búsqueda de nuevos paradigmas de calidad profesional del docente, de sus métodos y desempeño profesional..." (Chehaybar, 1999, p. 17).

Asimismo, organizaciones como la UNESCO (Organización de las Naciones Unidas para la Educación, la Ciencia y la Cultura) consideran que, para lograr potenciar los fines de la educación, el docente está en la capacidad de recurrir, de manera asertiva, a las actividades, métodos, materiales y otros medios que crea necesarios para la promoción de aprendizajes significativos. Esto significa que el docente, con formación pedagógica, podría estar en capacidad de transformar su conocimiento disciplinar en un aprendizaje de conocimiento entendible, práctico y con sentido, por cuanto recurre a la pedagogía como el instrumento que le facilita el conocer y el hacer el proceso educativo.

Lo anterior es una invitación a reflexionar sobre la formación docente como "un proceso permanente, dinámico, integrado, multidimensional, en el que convergen entre otros elementos la disciplina y sus aspectos teóricos, metodológicos, epistemológicos, didácticos, sicológicos, filosóficos e históricos, para lograr la profesionalización de la docencia” (Chehaybar, 1999, p. 17).

Con esto, es posible creer que gran parte de la profesionalización docente podría radicar en la continuidad de la formación del profesorado o formación permanente, y que resulte de ella el desarrollo profesional del profesorado, y, consecuentemente, del alumnado para que, de este 
proceso, surja "conocimiento al servicio de la vida, y elevamiento de la calidad de vida", es decir, aprendizajes significativos producto de modelos de enseñanza que "abarcarían tanto métodos y técnicas de enseñanza como los contenidos de saber que se proponen” (Flores,1994, p. XXV). Así, se podría suponer que del modelo pedagógico perseguido se derivan los métodos concebidos por Flores como "un conjunto afín de técnicas y procedimientos de enseñanza" para instrumentalizar la pedagogía, al igual que los contenidos requeridos, ambos responsables de implementar y viabilizar el currículo.

Se supone que la formación permanente se refiere a procesos de educación continua en los que el enriquecimiento de la disciplina y el conocimiento de modelos de enseñanza, en congruencia con la práctica de métodos, podrían ser la clave de la eficiencia en el proceso de aprendizaje como mediador activo entre el saber y el alumno. También, hace pensar que esos procesos de formación pedagógica, podrían ser el resultado de un mandato institucional o el mero interés del profesional docente para profundizar en aquellas áreas del conocimiento y de la práctica que su experiencia, en docencia o investigación, le sugieran para enriquecer y consolidar su desarrollo profesional.

Al respecto, se coincide con el criterio experto, el cual afirma que los procesos de formación permanente en el profesorado están concebidos "como una forma de prepararse para el dominio y actualización en la materia que se imparte y como la vía que permite adquirir elementos didácticopedagógicos que favorezcan la formación profesional" (Chehaybar, 1999, p. 84). Esto por cuanto consideramos que la teoría y las experiencias docentes promovidas en los procesos de educación permanente podrían ser construidas y validadas en la práctica pedagógica, para servir como un eventual insumo del modelo de enseñanza suscitado.

En cuanto a los modelos de enseñanza y su posible relación con los procesos de formación permanente, es posible pensar que ambos encuentran su punto de enlace, pues se parte del supuesto de que la formación permanente es un proceso continuo de reflexión sobre la práctica, que busca los significados que mejoren y enriquezcan la práctica pedagógica. De ahí que los modelos de enseñanza en congruencia con los métodos aplicados se conviertan en médula espinal, para garantizar el éxito de la formación docente en congruencia con una educación de calidad, tal y como lo considera Chehaybar (1999), que desde la acción el docente reflexiona sobre su práctica y va en busca de modelos de enseñanza como medios o métodos que le permiten replantearse y experimentar nuevas acciones pedagógicas.

Asimismo, expertos trazan su concepción de modelo pedagógico, el cual es definido como "la imagen o representación del conjunto de relaciones que definen un fenómeno, con miras a su mejor entendimiento" y "representan formas particulares de interrelación entre los parámetros pedagógicos" (Flores (1994, p. 160); además, este autor esboza en su obra diferentes tipos de modelos pedagógicos denominados por él como: a) modelo pedagógico tradicional promulgado por Skinner, el cual enfatiza la formación de carácter, y se considera normativo, ya que pretendía regular la transmisión de saberes y costumbres; de él derivan métodos transmisionistas de mera imitación y en los que la relación del maestro-alumno es vertical; b) modelo transmisionista conductista promovido por Rosseau y basado, meramente, en la fijación y en el control de objetivos instruccionales; en éste imperaba el método de fijación, refuerzo y control de aprendizajes instruccionales; c) modelo romántico, el cual concibe el desarrollo natural del individuo como la máxima y, a la vez, el método de la educación; d) modelo desarrollista, en el cual la meta educativa radica en que cada individuo acceda, progresiva y secuencialmente, a la etapa superior del desarrollo intelectual, de acuerdo con las condiciones con las que cuente cada uno y las necesidades que enfrente y e) modelo socialista, el cual propone el desarrollo máximo y multifacético de las capacidades e intereses del individuo. 
La reflexión y la acción en el campo pedagógico, por parte del profesorado en el proceso educativo, permite indagar en lo que se define como el papel de la autonomía docente desde lo que establece el currículo en conjunto, con lo que dicta la pedagogía en términos de productividad del conocimiento. Al respecto, Flores (1994) afirma que el proceso de productividad del conocimiento consta de tres momentos claves en los que el conocimiento se valora en la cotidianidad, luego en la reflexión y culmina en la afirmación. Todos estos momentos, según el autor, son vivenciados por el profesional para adueñarse, de forma autónoma, del conocimiento.

Así, se supone que se materializa la autonomía como parte del camino transitado por el colectivo docente en vías de apropiarse del conocimiento disciplinar y pedagógico, es decir, la dinámica productiva del conocimiento en función de la autonomía docente como parte del proceso educativo significativo, tanto para los docentes como para los discentes; y es en el practicum pedagógico donde se evidencia, precisamente, "la causa eficiente del aprendizaje".

\section{Currículo explícito y currículo oculto}

Si se parte de la existencia de un currículo explícito, el cual es definido por los expertos como aquel "currículo explícito u oficial que aparece claramente reflejado en las intenciones que, de una manera directa, indican las normas legales, los contenidos mínimos obligatorios o los programas oficiales, como los proyectos educativos de centro" (Torres, 2005, p. 198), es decir, un currículo del cual se deriven las políticas que definirán los programas, los contenidos y los proyectos educativos, en general. Habría que pensar dónde queda, entonces, el currículo oculto, aquel definido por el mismo autor como "el que hace referencia a todos aquellos conocimientos, destrezas, actitudes y valores que se adquieren mediante la participación en procesos de enseñanza y aprendizaje, en general, en todas las interacciones que suceden día a día en el aula y centros de enseñanza" (Torres, p. 10), es decir, el currículo vivido en el seno de la práctica docente, el cual no siempre apoya y aprueba lo que el currículo explícito dicta.

Este cuestionamiento nos conduce a reflexionar sobre la realidad vivida en el proceso educativo y lo que, en resumidas cuentas, sucede y prevalece en la cotidianidad del aula, con el fin de facilitar la comprensión de por qué, a pesar de todo lo antes mencionado, el estado actual de la educación pareciera no ser tan alentador; aun cuando el currículo explícito supone haber tratado de ordenar y de disponer, mediante una normativa clara, las acciones por seguir.

Sobre este tema, hay quienes afirman que el currículo oculto como corpus teórico "juega un papel destacado en la configuración de unos significados y valores de los que el colectivo docente y el mismo alumnado no acostumbran a ser plenamente conscientes" (Torres, 2005, p. 10). Asimismo, este autor considera que, en la medida que se le traslade la atención requerida al currículo oculto, se estarían mostrando los significados sociales y los efectos imprevisibles de las experiencias escolares, en las que se ven envueltos alumnos, alumnas y profesores. De esta forma, es posible creer que la puesta en evidencia y toma de conciencia de los valores, los principios y las acciones concebidas muchas veces como rutinarias, robotizadas y, consecuentemente, fosilizadas de la práctica pedagógica vivida en los salones de clase, como parte de la cotidianidad del acontecer educativo, podrían ser las nuevas preocupaciones que estarían obligando al currículo prescrito, en congruencia con sus artífices, a entender, a fin de garantizar un proceso educativo innovador.

A manera de conclusión, y coincidiendo con las palabras de Lundgren (1997), es de suma importancia que los artífices que dan vida a la educación universitaria, conozcan el conjunto de principios que nutren el currículo y la forma en que éstos inciden en los fines, en los contenidos y 
en los procesos educativos; esto por cuanto cada uno de ellos es eje fundamental para la promoción de un currículo universitario de calidad y de significancia.

\section{Referencias bibliográficas}

Blanco, N. (1997). El currículo: La importancia de conocer el origen de un concepto y unas prácticas. Almería, España: Programa Oficial de postgrado "Políticas educativas" Universidad de Almería.

Chehaybar, E. (1999). Hacia el futuro de la formación docente en educación superior. México, D.F: UNAM-CESU.

Díez y Román. (2004). Diseños curriculares de aula. México, D.F: Ediciones Nuevas Educativas de México.

Flores, R., (1994). Hacia una pedagogía del conocimiento. Bogotá, Colombia: Editorial McGrawHill.

Lundgren, U. P., (1997). Teoría del currículo y escolarización. Madrid, España: Ediciones Morata.

Menin, O. (2001). Currículo, Didáctica y Evaluación. Buenos Aires, Argentina: Ediciones Homo Sapiens.

Stenhouse, L. (2004). La investigación como base de la enseñanza. Madrid, España: Ediciones Morata.

Torres, J. (2005). El currículum oculto. Madrid, España: Ediciones Morata. 